Sarana, Gopala and Kharni P. Sinha

1976 "Status of Social-cultural Anthropology of India." in Siegel, Bernard J. (ed.) Annual Review of Anthropology, California: Annual Reviews Inc.

Thapa, T.S.

1974 "The Development of Sociology in Nepal." in Sharma, P.R. (ed.) . Social Science in Nepal. A report on the proceedings of a seminar on Social science in Nepal held at INAS in October 1973. INAS, Tribhuvan University, Kathmandu. pp. 27-38.

\section{"ROMANTICISM" AND "DEVELOPMENT" IN NEPALESE ANTHROPOLOGY ${ }^{1}$}

James F. Fisher

It has become almost a public mantra, repeated by high and low government officials, foreign observers of the contemporary scene, and increasingly, the citizenry at large, that "development" now occupies pride of place in the national agenda of Nepal. From that stance it is but a short step to the position that "development" is what anthropology should be all about in Nepal too; in this view, without such a development orientation anthropology would be merely a frivolous luxury the country can ill afford.

The preeminence of "development" having been thus established -- for the country and for the discipline -- the next point in the argument is that anthropologists in Nepal are uniquely situated to spot forms of social organization and decode cultural patterns, both of which are frequently seen to be obstacles to "development," with which myopic economists, provincial political scientists, and culture-bound psychologists have been unable to cope. The anthropologist, so attuned to the minute and exotic differences that exist between this ethnic group and the one in the next valley, will stride onto the scene and, like Manjusri at Chobar, cut through the developmental impasse that seems to stymie us at every turn.

Despite the cogency of this argument not all anthropology (so the critical line goes) is development-oriented. In fact, the besetting sin of most foreign anthropology (and until recently most Nepalese anthropology has been foreign) is that rather than being development-oriented it is just the opposite -- that is to say, it is entangled in the false consciousness of "romanticism" and, therefore, not relevant to the country's needs.

I should be clear from the outset on two points: one is that I agree wholeheartedly with the position of my colleagues in the Department of Sociology and Anthropology (including the 
contributors to this volume), which has been sharply articulated by Professor Bista: namely, that the first order of business for Nepalese anthropology is that it be bent to the service of the nation. The second point is that I myself am an unabashed and incurable romantic -- like many anthropologists, I am drawn to other cultures because I can't stand my own. The rest of this paper attempts to reconcile this apparent antinomy.

The romanticism charge has been leveled by several of my friends and colleagues. For example, my colleague, $\mathrm{Mr}$. Devkota, writes of the "unfortunate trend" of the "traditional romantic approach" which western anthropologists have introduced. For him it is "a matter of shame that western anthropologists are romanticizing our people like the bhakku" (animal for ceremonial sacrifice?). Instead Devkota calls for "action-oriented analysis which can provide means and schemes for the betterment of the concerned people's lot" (1984:50).

In a similar vein, Gauchan's recent M.A. thesis in Home Science (1986) suggested that the voluminous writings by foreign scholars on the Thakalis had often romanticized them. Dr. Harka Gurung wrote in a recently published essay that it was "romanticization of the rural" -- a notion introduced from developed countries -- not to recognize that rapid and extensive urbanization is an essential ingredient for successful development (1984:249). Professor Bista, in this volume, cautions Nepalese students against indulging themselves in "over-romanticized nostalgia."

Nor is the accusation of "romanticism" hurled only by Nepalese at foreigners. Sherry Ortner began her book on Sherpa ritual by saying:

"Nepal is certainly one of the more romanticized places on earth, with its towering Himalayas, its abominable snowmen, and its musically named capital, Kathmandu, a symbol of all those faraway places the imperial imagination dreamt about. And the Sherpa people ... are perhaps one of the more romanticized people of the world, renowned for their mountaineering feats, and found congenial by Westerners for their warm, friendly, strong, self-confident style."

$(1978: 10)$
The essential ingredient missing in all these views is an explicit statement of what is meant by either "romanticism" or "development," for without such an understanding such discussion can easily degenerate into either exhortatory sloganeering (a modern version of the tribal chant) or mere namecalling, neither of which advances Nepal's developmental interests. As for the definition of "development", we have been unusually unreflective and wishy-washy, even by the conventionally evasive standards of the academy. As no one seems to have a clear concept of what the definition is, we have tried to hide our ignorance by looking for an equivalent term in Nepali. Since there is no term in Nepali for "development," we have indulged ourselves in the ultimate obscurantism of ferreting out a Sanskirt word -- "vikas" (in Nepali, bikas) -- to use as a label for all the things we are doing, trying to do, or trying to prevent, in improving living standards in Nepal.

A working definition of development as it is currently practiced would include as essential components the fact that it 1) attracts large amounts of foreign currency, 2) most of which is used to buy foreign goods, or 3 ) employ foreigners (many of whom are unemployable in their own countries), to do jobs which, increasingly, many Nepalese are qualified to hold. (The final irony is that although many of these foreigners maintain a standard of living they could scarcely dream of in their own countries, they are paid a $25 \%$ bonus because Kathmandu is a "hardship post.") Add to that the open secret that most foreign aid benefits primarily the Nepalese elite, and one can define "development", not without reason, as the process by which the wealth of poor people in rich countries is transferred to the rich people of poor countries. I offer this characterization of "development" only to show the extent to which it has become an intellectual wasteland of vast proportions. Rather than merely farming ourselves out to the highest development bidder, we sociologists and anthropologists should look at development critically as part of an effort to cultivate this wasteland so that it yields more than it has so far.

While I think anthropology in Nepal can, should, and has to be "development" oriented, and while I agree that some 
scholarship has been "romantic," I also think that in casual use these terms are vacuous and that the former arguably includes as many sins as the latter. In what follows I propose a much boarder program for anthropology in Nepal, based on a revisionist understanding of "development" and "romanticism".

Whatever Nepalese critics may mean by it, I understand the term "romanticism" to refer to two distinct types of scholarly phenomena. The first is simply "inaccuracy" of a certain, systematic kind in ethnographic reporting. Since I have accused my friends and colleagues of being imprecise in their use of this term, let me give a specific example of what I mean by it.

Professor Furer-Haimendorf (1964) described the Sherpas as people unfettered by the hierarchical constraints of orthodox Hindu society and its concern with pollution and purity; in this view Sherpas are, unlike Hindus, free, open, democratic, and egalitarian. Later on Ortner discovered that Sherpas do indeed have an elaborate conception of pollution (1973) and that their society is fairly saturated with hierarchy (1978). Haimendorf's view of the Sherpas is romantic because it distorts ethnographic facts, by downplaying the importance of the khadeu/khamendeu distinction and eliminating Kamis from Sherpa society all together. This is akin to glorifying free Athenian society while neglecting the fact that it also included slaves. Thus the Sherpas become portrayed in an idealized, romanticized fashion -- as jolly little gnomes. I think I understand the reason for Haimendorf's error. He approached the Sherpas after a lifetime of research experience with tribal groups surrounded by the much more conspicuously hierarchical Hindus of peninsular India; lacking knowledge of the Sherpa language which would have given him the necessary clues, he therefore overlooked or minimized Sherpa concern with pollution and hierarchy. It is one of many kinds of ethnographic mistake, and we can see its source, but it is still a mistake that needs to be, and in this case has been, corrected.

But there is anther, significantly different kind of foreign anthropological reporting which has been labeled "romanticism." The second reason foreign researchers often strike Nepalese scholars as "romantic" is that the former are practicing in the field the same ancient and honorable tradition they preach in the classroom, namely the anthropological doctrine of cultural relativism.

The notion of cultural relativism goes back to the roots of American anthropology, to its founder, Franz Boas, and his students, Ruth Benedict and Margaret Mead. The basic idea of cultural relativism is that each culture has to be judged on its own merits and by its own values not by the ethnocentric yardstick of an alien, technologically more advanced, usually more Western culture. For Boas and Benedict, cultural relativism was an absolutely necessary antidote to seeing the world exclusively through Western eyes. It was also an effort to find positive value in the non-Western world, rather than scorning it as merely primitive and backward. It was an attempt to jolt the American public out of their gratuitous and arrogant assumptions of superiority and into the realization that parts of the world beyond American shores have positive contributions to make to our modest planet.

All Nepalese, whether they realize it or not, are immensely sophisticated in their knowledge and appreciation of cultural differences. It is a rare Nepalese indeed who knows how to speak only one language. Those who have not lived in the U.S. may find it hard to appreciate how a transcontinental, monolingual, monocultural milieu can construct a nearly impenetrable, self-serving, insufferably parochial worldview. Probably no other nation, with the possible exception of China, has been more arrogantly unquestioning of its own assumed superiority.

All this emphasis on cultural relativism sounds enlightened and progressive enough, but its implications are quite profound for both anthropology and development. For the Western anthropologist a prime objective becomes capturing the way of life of non-Western people in all sympathetic a light as possible. It is true that people in Nepal are very poor, and Bista correctly argues that the primary mission of Nepalese anthropology will be to contribute to the understanding and transformation of that poverty. 
That contribution is fundamental and critical, but there is more to say about the people of Nepal than that their average per capita income is low. One can also describe the positive aspects of their lives, including their sense of community and morality, their religion and worldview, their rituals, music, folklore, and sense of humor, their honesty, tolerance, and honor, and the meanings they construct of poverty and beauty, authority and oppression, beauty and violence, love and prestige. If the rest of the world has been consulted on these matters, Nepal also deserves to be entered into the record. Nepal's accomplishments deserve equal time with its problems. That is, one can identify and explain all the factors that contribute to human misery -- as Oscar Lewis (1951) did in the Mexican village of Tepoztlan -and still report and describe the elements that make life worth living -- and even emulating -- as Robert Redfield (1930) did in the same village. To stress a point, it is true that Mozart was impoverished, exploited, and in such poor health that he died well below the average life expectancy of Nepalese today, but that is not the only thing worth noting about him.

Cultural relativism also has implications for development. For if we want to measure other cultures by their own standards, "development" takes on a very different dimension. Viewed in this way, a given society may be already "developed" in ways that "don't count" in the development game. And to play that game successfully requires taking into account the assets a society already possesses as well as its liabilities. Nepalese were building (and planning) one of the great artistic civilizations of the world at a time when it would be an overstatement to say that British culture existed; astonishing feats of agricultural engineering on steep mountain slopes were being accomplished when Europeans were slaughtering each other in self-righteous Crusades -- the Hegelian slaughterbench of history par excellence. Development assistance may be necessary, but it needs to be given with a more historically informed humility and accepted with a stronger sense of previous accomplishments.

In addition to "anthropological romanticism" we need to consider the possibility of "reverse romanticism" -- that Nepalese planners, in trying to measure their society solely by the criteria of the World Bank, the IMF, or USAID, are romanticizing the
West. At the least we must acknowledge the spate of problems that has followed in the wake of modernization there. This is a modern version of what the sociologist Veblen (1915) identified as the privilege of historical backwardness. That is, there is a penalty for taking the lead, and those that follow can avoid the leader's mistakes. It is worth asking why it is that increasing numbers of tourists come to Nepal. The reason has to do with more than the beautiful mountains. The reason is that Nepal has retained something the West has lost in the process of becoming "developed," and we come here, among other places, looking for it. That the quest may be frequently misguided and romantic is a reflection on the wayward wanderer, not on Nepal.

What, then, does anthropology have to offer Nepal? One thing it can do is what it has always done -- cultural history, ethnography, symbolic and materialist analysis, and the like. But isn't this irrelevant to "development"? To argue yes is to argue that people are nothing more than so many producers and consumers of calories, or income (it does not matter which, since both should be increased.) But surely the nature of a group's basic culturel identity -- to cite just one example -- is as important as anything else in determining its future. I therefore suggest that a book like Mary Slusser's Nepal Mandala -- at one level arcane cultural history -- may have at least as much relevance to development in the long run as many small--scale studies of, say, agricultural productive, because the former helps clarify what a people are and have been -- necessary and insufficient preludes to determining what they will become.

Dr. Chaitanya Mishra has asserted (1984) that there is little point in a book devoted to such an exotic topic as spirit possession in the face of widespread disease and malnutrition. I disagree with his assessment on two grounds: one is that it is intellectual imperialism. That is, I believe that in development as with any other topic one should start with concerns most important to people "on the ground," and spirit possession certainly qualifies in this regard. This is my anthropological bias to take local-peoples' views seriously. But a second reason is simply that health conditions cannot be improved until local healing practices are well understood. An example from Khumbu illustrates this point. The Khunde Hospital is one of the most 
modern, well-equipped, superbly staffed hospitals in rural Nepal. But the Australian anthropologist John Draper reports that the hospital sees fewer patients now then it did 15 years ago. Why? Because a large panoply of traditional healers exist to whom Sherpas, in many cases and for complicated reasons, prefer to go for their ailments. Thus, while at first glance it may seem merely exotic or "romantic" to study traditional healers, in fact no advancement in the health of Nepal's citizens will be possible until their indigenous medical practices and beliefs are understood. In the first place, successful public health planning requires such knowledge; and in the second, it is at least an open, empirical question whether people are better served by traditional practitioners than we may assume.

My final example of "romanticism" is the much-maligned "ethnographic approach." As I have already damned FurerHaimendorf, let me now praise him. His monograph, The Sherpas of Nepal (published in 1964, it was the first ethnography of a Nepalese group) contains a section describing the civic, public-spirited institutions of Sherpa villages in Khumbu. One such institution is that of the by now well-known shing nawa, or forest wardens, whose job it was to enforce the ban on cutting green trees for firewood. When Sagarmatha National Park was established, or one might say imposed, some 12 years after the publication of Furer-Haimendorf's book, there was virtually no input from the citizens who would live within its boundary. Nor did the bureaucrats who established it bother to read FurerHaimendorf's ethnography. Had they done so, they might have been spared some of the difficulties that have plagued them ever since, particularly with regard to vastly inflated firewood prices and consequent raping of local forest lands. In 1982 the National Park belatedly recognized the value of the shing nawa and made a half-hearted attempt to reinstate them. But to his credit the ethnographer had got it right the first time, and good ethnographies have many such "relevant" contributions to make to development. The problem with ethnographies is not so much that they are romantic, but that they are unread. One of our primary goals should be to see that our work -- ethnographic or otherwise -- is read and used by those who make or implement policy.
Finally, I would like to close by arguing that there is still another contribution we anthropologists and sociologists can make. In addition to shedding light on the kinds of practices, beliefs, and institutions mentioned above, anthropology has a grand and glorious theoretical tradition which gives a large-scale, long-range perspective on humanity. The principles of evolutionary and world-wide cultural variability can help us escape from the myopia of minute field studies. Nepalese anthropologists must read case studies from other developing societies to understand the lessons others have to teach and to put them into a larger theoretical and comparative frame. Anthropology as a discipline, then, gives us the conceptual tools to explain contemporary change. We already have all the answers we need; what we need are the right questions.

What are the implications of this for our agenda?

One implication is that we need to look beyond our masses of statistics, our impeccable methodological formats, and our mountains of ethnographic facts, at the broader issues. Rather than simply producing ever-larger cohorts of what Dr. Chaitanya Mishra has elsewhere so aptly termed "bikas wizards," who sprout like weeds around every well-funded project or the latest development fad, anthropology and sociology need to produce people with some critical vision of the big picture. This will require a willingness to examine, for example, the large structural impediments Mishra astutely describes in his article in this volume, as opposed to merely continuing the desultory tinkering with anachronistic systems characteristic of so much developmental social science research and action.

There is a clear and present danger, therefore, in anthropology and sociology being co-opted by development agencies and organizations, in our becoming compliant social technicians in the service of bureaucrats rather than critical practitioners of our crafts. It is as tempting in Nepal as it is in the United States to put money only into "applied" research -projects that promise immediate results. But in doing so we neglect basic research, which in the long run may be more important and fruitful. The line between "basic" and "applied" research, or between "romantic" and "relevant" research, can be all too facilely drawn. 
Theory cannot be neglected because it determines what kinds of questions we will ask. For example, if human society is a seamless web, then we should not have to choose between studies of "kinship and marriage, religion and social control," which Bista wants to deemphasize, or ignore "ideology, values, and norms" in favor of "poverty, ecology, planning, resource management", as Bhattachan suggests. Topics like marriage and religion, or ideology and values, cannot be excluded from such vital topics as poverty and resource management, because the former represent fundamental categories through which people live and perceive the world and, if it comes to that, "develop." We cannot afford to ignore Max Weber's insight, enduring legacy, and monumental scholarship showing that these are crucial variables in the process of modernization.

Anthropology and sociology need to be concerned with the general questions and the universal problems that have inspired the minds of its best practitioners. It is not just a matter of anthropology's micro-studies vs. sociology's macro-studies; it is a matter of confronting timeless issues and searching for theoretical principles vs. grinding out chi-squares that some ministry or international agency needs to justify its existence. We need far more of the kind of historical, analytical, and theoretical framework which Mishra's essay in this volume represents. To avoid being either mystified or minimized, development must be understood in larger contexts.

To produce people with this kind of vision we need to expose our students to the great ideas and cross-cultural data that are the backbone of the field. Of course we need to be Nepaloriented, but neither can we ignore, simply because they are not Nepalese, the classic studies that have been done elsewhere in the world. To take one example: Colin Turnbull's classic ethnography of the pygmies of central Africa shows how they have achieved a remarkable and productive symbiotic adaptation to the rain forest. It illustrates the larger generalization that the hunting and gathering period of human existence provided the best-fed and healthiest humans in the history of our planet. That may sound like more romanticism, but it is only a prosaic fact of the evolution of our species. Anyone who reads Turnbull's book is compelled to wonder uncomfortably what "development" could possibly mean in the context of Bantu villages. But few development planners in Nepal will have seriously considered that rather than add the hunting-and-gathering Raute -- a similar group -- to the rolls of marginalized and immiserated peasants, it might be better to leave them alone -- which happens to be also their own stated performance. We ignore such options because of our bourgeois and ethnocentric assumptions (both Nepalese and American) that permanent houses and indoor plumbing are necessary for the good life, and that anyone who wanders through the forests hunting monkeys is automatically underdeveloped. That this option may be the most unlikely-to-beaccepted suggestion of all time should not deter us from making it. Anthropology is a subversive science.

At the other end of the scale one needs to look critically at examples of successful development elsewhere. The Punjab is a classic case of the successful installation of Green Revolution agricultural technology. It is also a war-torn, divided society. This is not an argument that stability should take precedence over other considerations -- indeed, successful development may be inherently destabilizing. But it does indicate that we should not allow spectacular technology to blind us to its painful repercussions.

What I recommend, therefore, is that in our training we keep track of world-wide developments in our fields, adding to our arsenal those that will aid Nepal. I also recommend that when setting our research priorities we take into account the sheer bulk of anthropologists and sociologists who now do research in Nepal. Given the enormous quantity of sociologists and anthropologists, both foreign and Nepalese, now willing, eager, and able to do research in Nepal, it is not necessary to choose between "basic" and "applied" research, even if that distinction were more sensible than it seems to first glance. With the anthropologist population approaching a density of one in every village, there is room for all sorts of studies. If someone wants to study spirit possession, or the history of a temple, or the origins of landlessness, or resource management, the only wise restriction is that it be done by well-trained people sensitive to the developmental implications of their interests. Fortunately the Central Department of Sociology and Anthropology is now producing such scholars.

Let a hundred flowers bloom. In the era of development, we need not fear a shortage of scholars who will fasten their sights on it. 
1. Thanks are due to Krishna Bahadur Bhattachan and Verne A. Dusenbery for their helpful comments on an earlier version of this chapter.

\section{REFERENCES}

Devkota, Padam Lal.

1984 "Critique on Development of Infrastructure and Programme in Anthropology in Nepal" in Social Sciences in Nepal: Infrastructure and Programme Development. Institute of Humanities and Social Sciences, Tribhuvan University, Kirtipur.

Furer-Haimendorf, Christoph von.

1964 The Sherpas of Nepal. Berkeley: University of California Press.

Gauchan, Yasso Kanti.

1986 Socio-Cultural Change in Thakali Society: An EthnoSociological Study of the Thakalis of Kathmandu. Kathmandu: Tribhuvan University, Home Science Department, M.A. dissertation.

Gurung, Harka.

1984 "Afterword" in Nepal: Dimensions of Development. Sahayogi Press.

Lewis, Oscar.

1951 Life in a Mexican Village: Tepoztlan Restudied. Champaign-Urbana: University of Illinois Press.

Mishra, Chaitanya.

1984 "Social Research in Nepal: A Critique and a Proposal" in Contributions to Nepalese Studies, vol. 11, \#2.

Ortner, Sherry B.

1973 "Sherpa Purity" in American Anthropologist, vol. 75, \#1.

1978 Sherpas Through Their Rituals. Cambridge: Cambridge University Press.

Redfield, Robert.

1930 Tepoztlan - A Mexican Village. Chicago: University of Chicago Press. 
Slusser, Mary.

1982 Nepal Mandala. Princeion: Princeton University Press.

Turnbull, Colin M.

1961 The Forest People. New York: Simon and Schuster.

Veblen, Thorstein.

1915 Imperial Germany and the Industrial Revolution. New York: Macmillan Company.
MIGRATION, ADAPTATION AND SOCIO-CULTURAL CHANGE: THE CASE OF THE THAKALIS IN POKHARA ${ }^{1}$

\section{Ram Bahadur Chhetri}

\section{Introduction}

The purpose of the present paper is to discuss adaptation, cultural continuity, and change among the immigrant Thakalis in Pokhara, Nepal. The Thakali community has attracted considerable attention in recent years (Bhattachan 1980, Chhetri 1980, Furer-Haimendrof 1966, 1981; Gauchan and Vinding 1977; Iijima 1963; Manzardo and Sharma 1975; Messerschmidt 1975; Vinding 1984). However, studies dealing specifically with adaptation and change among the migrant Thakali groups in various parts of Nepal are lacking2. Migration is not a new phenomenon for the Thakalis. In the past most of them were involved in a process which may be characterized as cyclic or circulatory migration 3 . This brought them into contact with other communities in the lowland villages, towns, and cities of Nepal, and thereby initiated among them a process of social and cultural change and adaptation.

Some important arguments emerge from the discussion that follows which may be pointed out in the beginning. First it is argued that adaptation is a two way process, i.e., it involves an interaction between the immigrants and the host society. In this process both parties undergo adaptational changes, although one of them may change more than the other, which leads many of us to view the process of adaptation from the migrant's point of view only. Second, the process of adaptation may not necessarily lead to the assimilation of the in-migrants in the host culture and society. This becomes more true when the host society itself is multi-ethnic in character (as is Pokhara) and also when inmigrants in question mostly share the same social, cultural, linguistic and religious backgrounds (as in the case of the Thakalis in Pokhara) and originate from the same geographical

\footnotetext{
* This article was published earlier in a slightly
} different form in Contributions to Nepalese Studies. 13(3) : 239-59. 